Tezel, K. V. (2020). Bir şiir Viki'si kullanmak: Bu ortam dijital bir çağda İngilizce öğretmen adaylarının şiir yazma ve şiir yazmayı öğretme konusunda meslekî bilgi öğrenmelerine nasıl destek olabilir? Ana Dili Eğitimi Dergisi, 8(4), 1552-1563.

\begin{tabular}{c}
$\begin{array}{c}\text { Ana Dili Eğitimi Dergisi } \\
\text { Journal of Mother Tongue Education } \\
\text { www.anadiliegitimi.com } \\
\text { Geliş/Received: } 10.10 .2020 \text { Kabul/Accepted:16.10.2020 } \\
\text { Çeviri / Translation }\end{array}$ \\
\hline
\end{tabular}

\title{
Bir Şiir Vikisi Kullanmak: Bu Ortam Dijital Bir Çağda İngilizce Öğretmen Adaylarının Şiir Yazma ve Şiir Yazmayı Öğretme Konusunda Meslekî Bilgi Öğrenmelerine Nasıl Destek Olabilir?*
}

\begin{abstract}
Öz Kadir Vefa TEZEL ${ }^{* *}$

Bu makalede bir grup İngilizce öğretmeni adayının katılımıyla şiir hakkında işbirlikli bilgi yapılandırmak üzere oluşturulan çevrimiçi bir Viki topluluğu ile ilgili yapılan nitel bir çalışmanın bir bölümünü sunuyoruz. Makalemiz öğretmen adaylarının dijital bir ortamda yazma deneyimlerini ve yazar olarak kendileriyle ilgili algılarını araştırmaktadır. Biz özellikle hizmet öncesi yılları boyunca Birleşik Krallık ve Kanada'da farklı ortamlarda çalışan iki grup öğretmen tarafından bu dijital ortamda girişilen (hem işbirlikli hem de bağımsız) şiir yazma süreçlerine odaklanmaktayız. Çok çeşitli iletişim olanaklarını içinde barındıran Viki ortamının bu öğretmenlere şiir yazmayı öğrenmeleri için sunduğu imkânları (Laurillard, Stratford, Lucklin, Ploughman ve Taylor, 2000) araştırıyor ve bu imkânların öğretmenlerin yaptıkları işbirlikleri ve yazdıkları şiirler üzerindeki etkisini sorguluyoruz. Bu çalışmada öğretmen adaylarının Viki yazışmalarını analiz ederken yazar olarak kendilerini nasıl biçimlendirdiklerini ve dijital bir üçüncü alanda birbirlerinin devam eden çalışmalarına nasıl müdahale ettiklerini gözlemlemekle ilgilendik. Ayrıca, Viki'nin kendilerine eğitim aldıkları yılda şiir yazma öğretimi konusunda meslekî bilgi öğrenmelerine nasıl destek olduğunu ve bu desteğin yazma öğretmenleri olarak gelecekteki sınıf içi uygulamaları için getirebileceği sonuçları araştırmak istedik.
\end{abstract}

Anahtar Kelimeler: İşbirliği, dijital diyalog, hizmet öncesi öğretmen eğitimi, çevrimiçi topluluk, şiir, şiir pedagojisi, meslekî bilgi öğrenme, Viki, şiir yazma

\section{Using a Poetry Wiki: How Can the Medium Support Pre-service Teachers of English in their Professional Learning about Writing Poetry and Teaching Poetry Writing in a Digital Age?}

\begin{abstract}
In this paper we report on one aspect of a qualitative study about an online wiki community, which was developed to build collaborative knowledge about poetry among a group of pre-service English teachers. Our paper explores pre-service teachers' experiences of writing in a digital medium and their perceptions of themselves as writers. We focus specifically on the processes of poetry writing (both collaborative and independent) undertaken in this digital medium by two groups of teachers, who were working in contrasting settings in the UK and Canada during their pre-service year. We investigate the affordances (Laurillard, Stratford, Lucklin, Plowman, \& Taylor, 2000) that a multimodal, wiki environment offered these teachers for learning about poetry writing and question the impact that these affordances have had both on the teachers' collaborations and the poetry they wrote. In analysing the pre-service teachers' wiki writings we were interested to
\end{abstract}

\footnotetext{
${ }^{*}$ Çeviri Makalesi. Eser yazarlarından yazılı izin alınarak çevrilmiştir. Çevirisi yapılan makalenin orijinal künyesi şu şekildedir: Dymoke, S. and Hughes, J. (2009) 'Using a poetry wiki: how can the medium support pre-service teachers of English in their professional learning about writing poetry and teaching poetry writing in a digital age' English Teaching: Practice and Critique, 8 (3), 91-106.

** Dr. Öğretim Üyesi. Bolu Abant İzzet Baysal Üniversitesi, Eğitim Fakültesi, Yabancı Diller Eğitimi Bölümü, Bolu, vefa2000@gmail.com , ORCID: 0000-0002-2636-1221
} 
observe how they shaped themselves as writers and intervened in each other's work in progress within a digital third space. We also wanted to explore how the wiki had supported their professional learning about the teaching of poetry writing during their training year and the implications that this support could have for their own future classroom practice as teachers of writing.

Keywords: Collaboration, digital dialogue, Initial Teacher Education, online community, poetry, poetry pedagogy, professional learning, Viki, writing poetry

\section{Giriş}

Bu makalede bir grup İngilizce öğretmen adayının katılımıyla şiir hakkında işbirlikli bilgi yapılandırmak üzere oluşturulan çevrimiçi bir Viki topluluğu ile ilgili yapılan nitel bir çalışmanın bir bölümünü sunuyoruz. Makalemiz öğretmen adaylarının dijital bir ortamda yazma deneyimlerini ve yazar olarak kendileriyle ilgili algılarını araştırmaktadır. Biz özellikle hizmet öncesi yılları boyunca Birleşik Krallık ve Kanada'da farklı ortamlarda çalışan iki grup öğretmen tarafından bu dijital ortamda girişilen (hem işbirlikli hem de bağımsız) şiir yazma süreçlerine odaklanmaktayız. Çok çeşitli iletişim olanaklarını içinde barındıran Viki ortamının bu aday öğretmenlere şiir yazmayı öğrenmeleri için sunduğu imkânları (Laurillard, Stratford, Lucklin, Ploughman ve Taylor, 2000) araştırıyor ve bu imkânların onların yaptıkları işbirlikleri ve yazdıkları şiirler üzerindeki etkisini sorguluyoruz. Bu çalışmada öğretmen adaylarının Viki yazışmalarını analiz ederken yazar olarak kendilerini nasıl biçimlendirdiklerini ve dijital bir üçüncü alanda birbirlerinin devam eden çalışmalarına nasıl müdahale ettiklerini gözlemlemekle ilgilendik. Ayrıca, Viki'nin eğitim yıllarında şiir yazma öğretimi konusundaki meslekî bilgi öğrenmelerine nasıl destek olduğunu ve bu desteğin yazma öğretmenleri olarak gelecekteki sınıf içi uygulamaları için getirebileceği sonuçları araştırmak istedik.

Analiz edilen veriler, Viki ortamı aracılığıyla oluşturulan taslak şiirlerden ve bu yazılarla ilgili taslak oluşturma ve iletişim yoluyla evrilen dijital diyaloglardan oluşmaktadır. Yarı yapılandırıımış anket yanıtları da incelenmiştir. Öğretmenlerin yazı ve tartışmaları üzerinde yaptığımız analiz, öğretmen adaylarının bir Viki sayesinde işbirliği yaparak dijital okuryazarlıklarını geliştirebilecekleri bazı yolları göstermektedir. Bulgular, bu sosyal yazılımın kullanımının daha da iyileştirilmesi için tavsiyeleri ve Viki'nin bir araç olarak öğretmenlerin meslek hayatlarının başında şiir yazma öğretimi konusunda meslekî bilgi öğrenmelerini desteklemede potansiyel değerini gösteren sonuçları içermektedir.

\section{Dijital Çağda Şiir Öğretimi}

Şiir öğretimi uzun zamandır hem öğretmen adayları hem de çok farklı uluslararası ortamlarda çalışan deneyimli öğretmenler için İngilizce müfredatının kendine özgü pedagojik zorluklar çıkaran bir yönü olarak kabul edilmektedir (Mathieson, 1980; Harrison \& Gordon, 1983; Benton, 1984; Andrews, 1991; Thompson, 1996; Dymoke, 2000; Hughes, 2008). Kanıtlar, en azından İngiltere ve Galler'de, şiirin İngilizce müfredatının en az öğretilen kısmı olduğunu göstermektedir (Ofsted, 2007). Öğretmenlerin sınıfta sınırlı sayıda şiir metni kullandıkları ve özellikle ilkokul çocukları için kendi deneyimleriyle doğrudan bağlantılı şiirler okumaları veya yazmaları için çok az fırsat tanıdıkları söylenmektedir.

Hizmet öncesi öğretmen eğitimi, bir öğretmenin sınıfta şiir türünün başarılı bir şekilde ele alınması konusunda güvenini geliştirmede çok önemli bir aşamadır. (5 ila 19 yaş aralı̆̆ında ders vermek için eğitilen) birçok İngilizce/dil becerileri öğretmen adayı üniversite eğitimi öncesi veya ön lisansta kendi başlarına şiir yazma konusunda çok sınırlı deneyime sahiptir (Ray, 1999; Dymoke, 2007) ancak, örnek olarak, Birleşik Kralık ve Kanada'da, kendilerinden mutlaka sınıfta şiir ve diğer edebi türlerin yazar ve okuru olarak örnek teşkil etmeleri beklenir (bakınız: Saskatchewan Eğitim 1998 ve Çocuklar, Okullar ve Aileler Dairesi 2008 müfredat politika belgeleri).

Her ne kadar öğretmenin kendi sınıfında bir yazar da olması gerektiği beklentisi, ana dili İngilizce olan tüm ülkelerde müfredat politikası belgelerine dâhil edilmese de, öğretmen-yazarın öğrencilerin kompozisyon becerilerinin gelişimi üzerindeki olası etkisi onlarca yıldır uluslararası bir tartışma konusu olmuştur. Örneğin, Şair Kenneth Koch'un $(1970,1973)$ New York'taki bir devlet okulunda şiir yazma öğretimini anlatan yazıları ve Donald Graves'in $(1981,1983)$ New Hampshire'da küçük çocukların yazmaları ve yazdıkları ile ilgili olarak yapılan sınıf içi öğretmen-öğrenci görüşmeleri 
üzerine olan araştırmaları hem yaygın olarak tartışılmış hem de örnek alınmıştır. Birçok İngiliz araştırmacı ve şair, öğretmenlerin hem şiir yazarı hem de okuru olarak örnek olmalarına duyulan ihtiyaç üzerinde özellikle durmuştur (Stibbs, 1981; Dunn, Styles \& Warburton, 1987; Nicholls, 1990; Yates, 1999). Nicholls, "çocukların yetişkinlerin de kelimelerle boğuştuğunu bilmeleri gerektiğini" söylemektedir (1990, s. 27). Stibbs, öğretmenlerin yazarak yazmayı teşvik etmelerini ahlaki bir zorunluluk ve bir çocuğun sınıf içi deneyiminin hayati bir parçası olarak görür: "Öğretmenler bunu yapmadıkça, çıplaklar kolonisindeki terzi mankeni olurlar; bunlar çok yanlış tutumlardır" (1981, s. 49.) Koch'un kendi çalışmaları üzerinde etkisi olduğunu açıkça belirten Yates, mümkün olan her fırsatta çalıştığı ortaokuldaki öğrencilerle birlikte yazdığını söyler ve şöyle der: "Yazdıklarım ille de iyi olmaz ama bu önemli değil; yazmak, risk almak ve bir şeyler denemektir" (Yates, 1999, s. 2).

Şu açık ki, öğretmenlik mesleğinde yeni olanlar henüz cebelleşmeye, kendi zayıf yönlerini tüm çıplaklığıyla göstermeye ve risk alacak cesarete sahip olmayabilirler. Bu tür riskleri almak için destek görecekleri fırsatların verilmesine gerçekten intiyaç duyabilirler. Dymoke $(2000,2007)$ tarafından yapılan araştırmada, eğer öğretmen adayları öğretmenlik kariyerleri boyunca şiir pedagojisi hakkında kendilerine destek olacak önemli bir farkındalığı geliştirmelilerse, kendilerine (şiir yazma etkinlikleri de dâhil olmak üzere) yaratıcı benliklerini geliştirmelerine olanak sağlayacak yaratıcı yaklaşımları deneyimlemeleri için erken eğitim fırsatları verilmesi gerektiği sonucuna varılmışır.

Ayrıca, hizmet öncesi öğretmenler kendi öğrencilerini şiir konusunda gayrete getireceklerse, o zaman, dijital bir çağ için şiirin İngilizce müfredatındaki yerini gerekçeleri ile göstermeli ve yenileyebilmelidirler. Yaratıcılık ve yazma üzerine yapılan araştırmalarını anlatan Grainger, Goouch ve Lambirth, şiirlerin "sadece gücü ve güzelliği gibi bazı nitelikleri tek bir bakış açısından görülen kafese konulmuş aslanlar gibi" olması gerekmediğini söyler (Grainger ve ark. 2005, s. 141). Şair Adisa şöyle yazar: "Şiir kâğıda yazılır, ancak orada yaşamaz" (2002, s. 128). Bu alıntıların ikisi de, bizim görüşümüze göre, şiirin 21.yüzyıl müfredatına dâhil edilmesinin önemli bir gerekçesi olan güçlü, dinamik ve çok ortamlı doğasına işaret etmektedir. Biz yalnızca şiirin günlük hayatın ahengi içine şarkı sözleri, Twitter mesajları ve kısa mesajlar yoluyla, sokak dili, protesto miting sloganları, futbol takımlarının tezahürat şarkıları ve reklamların akılda kalıcı kısa şiirli müzikleri aracılığıyla nasıl gömülü olduğunu düşünmeli ve şiirin hakemli şiir yarışmalarında, mikrofonda şiir okuma etkinliklerinde, YouTube yayınlarında nasıl icra edildiğinin ve Şiir Arşivi (www. poetryarchive.org) gibi web siteleri aracılığıyla nasıl erişildiğinin, basıldığı sayfada sonsuza dek mahsur kalan bir araç olmadığının, neşe veren, birden çok ortamda var olan canlı bir araç olduğunun farkında olmalıyız. Bunlara ek olarak, bu etkinliklerin çoğunun gösterdiği gibi, şiir sadece Fildişi Kulesi'ndeki şaire özel bir alan değil, aynı gerçek veya sanal ortamda, birlikte çalışan kişiler tarafından ortak yazılabilen, icra edilebilen, kaydedilebilen veya filme alınabilen bir tür (bkz. örneğin, Gioia, 2004), işbirliğine olanak veren bir araç olabilir. Bizler bu Viki projesinin, şiir türünün bu dinamik, çok ortamlı ve işbirlikçi potansiyeline vurgu yapmasını ve bunlarla yeni bir öğretmenler grubunu cezbetmesini umut ettik.

Araştırmamız, Lankshear ve Knobel (2003), Knobel ve Lankshear (2007), Gee (2004) ve Steinkuehler'in (2005) çalışmalarını içeren "yeni" okuryazarlık çalışmaları yaklaşımı içerisinde yer alan kuramlar tarafından desteklenmektedir. Bunlar, farklı sosyal bağlamlarda gelişen okuryazarlık uygulamaları ve bu uygulamalar ve bağlamlarla ilgili değerlerle ilgilidir. Biz başta dijital metinlerin, özellikle de şiirlerin, onları oluşturanların kullandığı alanlar ve dijital iletişimin eş zamanlı olarak bireyin hem yazar hem de okuyucu olarak oluşması, yansıması, işbirliği yapması ve sergilenmesi için sağlayabileceği olanaklarla ilgileniyoruz. Metin kelimesi, Latince dokumak anlamına gelen "texere" fiilinden türemiştir. Dijital bir alanda, çok ortamlı bir metin, o metnin aynı zamanda kullanıcıları ve okuyucuları olan birçok oluşturucu tarafından dokunabilir. Metin, birçok farklı iplik ve ortam kullanılarak birleştirilebilir veya "yeniden düzenlenebilir" (Knobel \& Lankshear, 2007, s. 8). Başka oluşturucular tarafından sık sık yeniden dokunabilir, yeniden tasarlanabilir (New London Group, 1996) ve değiştirilebilir.

Bu işbirlikçi sürecin içinde bir "ilişkililik" duygusu vardır (Knobel \& Lankshear, 2007, s.13), şöyle ki: Metin oluşturmaya katılan kişiler bunu "ilgi alanları" (Gee, 2004, s. 83) veya "yeni üçüncü alan" (Steinkuehler, 2005, s. 17) içinde yaparlar. Gee bu tür alanların iş ve ev dışında bulunduğunu, okullarda öğrenmenin gerçekleştiği mekânlardan çok farklı olduğunu, çünkü katılımcılar arasındaki ilişkilerin 
bağlamsal faktörlerden ziyade öncelikle ilgi yoluyla geliştirildiğini söyler. Bu tür grup oluşumları yalnızca metin oluşturmanın nerede ve ne zaman gerçekleşebileceğine dair geleneksel algıları sorgulamakla kalmaz, aynı zamanda acemi/öğrenci ve uzman/öğretmenin kimlik ve ilişkilerini de sorgular.

Dijital teknolojilerin sınıf bağlamlarında kullanımı [Wyatt-Smith \& Kimber, (2005), Burn \& Durran, (2007) dâhil] birçok araştırmacının gösterdiği gibi uluslararası düzeyde gelişmektedir. Tüm alanlarda mesleğe yeni başlayan öğretmenlerin, gittikçe artan bir şekilde dijital teknolojiye erişmeleri ve usta kullanıılar hâline gelmeleri beklenmektedir. Örneğin, bakınız, İngiltere'de öğretmen adayları tarafından uyulması gereken Profesyonel Standartlar (Eğitim ve Geliştirme Ajansı, 2007 - Training \& Development Agency, 2007), bilişim ve iletişim teknolojilerinin (ICT) Ontario İngilizce Müfredatına dâhil edilmesi (Ontario Eğitim Bakanlığı, 2007 - Ontario Ministry of Education, 2007) ve "yeni öğretim fırsatlarının" mevcudiyetinin tasdiki ve "Avustralya müfredatının şekli: İngilizce (The shape of the Australian curriculum: English) içinde yer alan, Avustralyalı öğretmenler için dijital teknolojilerin ortaya çıkardığı erişim sorunları (Ulusal Müfredat Kurulu, 2009, s. 15 - National Curriculum Board, 2009, p. 15).

Ancak bu, kullanımının öğrenmeyi teşvik etmenin tek veya her zaman en etkili yolu olduğu anlamına gelmez. Öğretmenler, öğrencilerinin öğrenmeye katılmaları için dijital ve diğer teknoloji türlerini kullanıp kullanmama, onları ne zaman ve nasıl kullanmaları konusunda bilinçli seçimler yapabilmeleri için ciddi olarak düşünmelerini sağlayacak şekilde desteklenmelidir. Öğretmenler teknolojinin sadece müfredatın önceden var olan yaklaşımları ve müfredatın çeşitli yönlerini yansıtıp yansıtmadığını ya da elde edilebileceklere değer katıp katmadığını ve öğrenme için yeni fırsatlar ortaya çıkarıp çıkarmadığını göz önüne almalıdır (Hennessey, Ruthven \& Brindley, 2003). Ayrıca, öğretmenler öğrencilerinin bilgi düzeyleri hakkında varsayımlarda bulunmaktan kaçınmalıdırlar (Buckingham, 2003). Buna ek olarak, Lewis bize müfredat eğitiminin tek başına yeterli olmayacağını hatırlatır: öğretmenler, potansiyellerini tam olarak anlamak istiyorlarsa, dijital teknolojilerden kaynaklanan "yeni düşünce yapısı, uygulamalar ve kimlikler" (Lewis, 2007, s. 230) ile yakından ilgilenmeye başlamalıdırlar. Öğretmen adaylarının dijital teknolojilerin potansiyeli ve kullanımlarıyla ilgili konular hakkındaki anlayışlarını geliştirmelerine destek olma ihtiyacı, aday öğretmenler grubu ile Viki projesini başlatmamızın en önemli nedenlerinden biridir.

Sosyal yazııımlar kullanımı yoluyla (bloglar ve Vikiler gibi) birçok farklı bağlamda çalışan öğrencilere sağlanan fırsatların türleri ve kalitesi üzerine araştırmalar hızla artmaktadır (bakınız, örneğin: Doe, 2006; Richardson, 2006; Hauser, 2007; Wheeler \& Wheeler, 2009; Davies \& Merchant, 2009). Fakat bizler kendi araştırmamız dışında, özellikle şiir öğretiminin herhangi bir yönünü inceleyen başka bir araştırma bulamadık. Lamb (2004), bir Viki'nin ilk olarak uygulanmasının ders uygulamaları ve normlarının doğruluğunu nasıl tartışmaya açabileceğini söylerken, Vratulis ve Dobson (2008) bir dizi standarda yanıt vermek için birlikte çalışan bir grup öğretmen adayına Viki ortamının sağladığı sosyal hiyerarşi ve sosyal uzlaşıların doğasını araştırmaktadır. Fountain'ın (2005) Viki pedagojisi ile ilgili literatüre genel bakışı, nasıl işbirliği yapılacağına ve/veya işbirliğine, motivasyona, yaratıcılığa ve yeniden teçhizatlanmaya karşı direnişe odaklananlar dâhil olmak üzere, özellikle çalışmamızla ilgili görünen bir dizi pedagojik kaygıya işaret etmektedir.

Buna ek olarak, bu araştırma pedagojik bilginin geliştirilmesine ilişkin olarak Shulman'ın (1986) Mesleki Alan Bilgisi, Pedagojik Alan Bilgisi ve Müfredat Bilgisini kapsayan kavramsal çerçevesi, Grossman'ın (1991) ABD'deki öğretmen adaylarının yönelimlerine ve hizmet öncesi öğretmen eğitimi veren hocaların öğretmen adaylarııın alan ve sınıf uygulamaları hakkındaki bilgi ve inançlarını gözden geçirmelerine yardımcı olmadaki rolüne odaklanması ve Gudmundsdottir'in (1995) öğretimde kullanmak amacıyla metinleri yeniden yapılandırmak için "Pedagojik olarak arayan gözler" in gelişimini tarif ettiği teorik perspektiflerle desteklenmektedir.

\section{Viki Nedir?}

Illk olarak 1995 yılında geliştirilen Vikiler blog türleridir. İsimleri, Hawai dilinde "hızlı" anlamına gelen bir kelime olan "wikiwiki" den türetilmiştir. Bir Viki çok hızlı bir şekilde oluşturulabilir. (Örnek olarak: www.pbwiki.com adresine gidin ve "eğitimciler" bölümündeki adımları izleyin; 5 dakika içinde yapım aşamasında olursunuz). Viki kullanıcılarına sunulan imkânlar çok ve çeşitlidir. Çevrimiçi işbirliğine 
dayalı kompozisyon yazmayı bir blogda başarılabilecek olan şeyleri aşacak şekilde kolaylaştırırlar. İnsanlar dijital ortamda bir Viki topluluğunun üyeleri olarak buluşabilirler. Dijital bir metin oluşturma konusunda yaratıcı bir şekilde işbirliği yapabilir ve/veya başkaları tarafından oluşturulan dijital metinlere düzenleme yapmak için doğrudan müdahale edebilirler ve hatta başka bir kişinin eserini silebilirler. Devam eden işler hakkında dönüt verebilir, bilgi paylaşabilir veya farklı sayfalar veya harici kaynaklar arasında bağlantı kurabilirler. Bu topluluğa üyelik, kendini üye yapma, sayıyla sınırlı olmayan üyelik sayesinde katılma veya (bizim durumumuzda olduğu gibi) açıkça tanımlanmış bir kullanıcı grubu yoluyla olabilir. Bir topluluğun dışındaki diğer okuyucular da Viki'ye göz atabilirler. Ancak, yalnızca katılımcılar paylaşımda bulunabilir veya birbirlerinin çalışmalarını düzenleyebilirler.

Vikinin, üzerine yeniden yazı yazılmış parşömen anlamına gelen "palimpsest" (Fountain, 2005) olarak tanımlanması, Viki sayfaları, gelişimlerinin her aşamasında okunabilecekleri ve yeniden gözden geçirilebilecekleri için, çok uygun görünmektedir ve bu, taslakların değerlendirilmesini ve onlara yapılan müdahaleleri kolaylaştıran bir özelliktir. Viki'nin en önemli örneği, dünyanın her yerindeki yabancılar tarafından yazılan ve yeniden yazılan 2,2 milyondan fazla madde içeren çevrimiçi bir ansiklopedi olan Wikipedia'dır. Wikipedia'nın doğasının ve sayfalarının düzenlenme yöntemlerinin başlangııından bu yana çarpıcı biçimde değiştiği iddia edilmektedir (Johnson, 2009). Birleşik Krallık ve ABD'deki sınıf Vikiler'i üzerinde yaptığı analizde, Carrington Vikiler için bir dizi "temel kullanımlar" belirlemiştir (Carrington, 2009, s. 73). Bunlar, bilgiyi yönetmek, anlatılar oluşturmak, kaynakları birleştirmek ve bağlantılar ve sözlüklerin kullanımı yoluyla mevcut metin'e değer katmaktır. Bu Viki şiir projesinde, birincil amacımız anlatılar oluşturmaktı. Ancak proje, Carrington tarafından araştıılan diğer kullanımların bazılarını da kapsadı.

\section{Araştırma Yöntemi}

Eylül 2007 'de, eğitimlerinin süreceği akademik yıl boyunca İngiltere ve Kanada'daki yüksek öğrenim kurumlarında bulunan (22 ila 42 yaş aralığında) 56 lisans ve lisans üstü öğrenim gören ve mesleğe girmeye hazırlanan İngilizce ve dil becerileri öğretmen adayından oluşan karışık, kolaylıkla örnekleme yoluyla oluşturulan bir örnek grup tarafından kullanılmak üzere bir şiir Viki'si oluşturuldu. Dört kişi, daha önce bir Viki kullanma deneyimine sahipti (bunlardan ikisi için bu deneyim Wikipedia'nın kullanımı anlamına geliyordu). 52 katılımcının ise herhangi bir deneyimi yoktu, ancak önemli sayıda kişi Facebook, MySpace veya canlı sınıf (sanal öğrenme ortamı) gibi sosyal yazıılımlara katkıda bulunmuştu. Bir kişi kendisinin Viki konusunda bakir olduğunu belirtti; diğeri dersten önce Viki kelimesini hiç duymadığını söyledi. Ilginçtir ki, bu gençlerin her ikisi de Viki'nin en aktif katılımcılarından oldu. Önceki şiir yazma deneyimleri açısından, aday öğretmenlerin \%20'sinden daha azı diğer okuyucularla çalışmalarının taslaklarını paylaşmıştı; yaklaşık \%50'si -birçok durumda çok sınırlı bir sayı olsa da- şiir yazma deneyimine sahipti. Öğretmen adaylarının şiire karşı tutumları ve bu türle ilgili önceki deneyimleri ve bilgileri, bu çalışmadan kaynaklanan ikinci bir makalede incelenmiştir (Hughes \& Dymoke, baskıda).

Viki'yi oluştururken, yukarıda ana hatları belirtilen şiir eğitimi ile ilgili önceki araştırmalarda belirlenen, bu ortamın öğretimi ile ilgili konular ışığında, onun öğretmen adaylarının şiirin çeşitli yönlerini öğretme konusundaki becerilerini ve güvenlerini geliştirmek için sunabileceği olanakları araştırmak istedik. Amaç, öğretmen adayları grubunun:

- şiirin doğası ve başkaları tarafından nasıl tanımlandığı hakkındaki düşüncelerini,

- kendi şiir zevklerini ve bunların nasıl geliştirildiğini,

- şiir öğretimiyle ilgili ilk deneyimlerini,

- şiir öğretimi kaynaklarını,

- birbirlerinin çevrimiçi şiir taslakları ve düzenlemelerini paylaşmasıydı.

Bu şekilde, Viki, İngilizce müfredatının bir parçası hakkında, onların gelişmekte olan pedagojik bilgilerine, sınıf içi uygulamalarına ve inançlarına destek olabilirdi. Buna ilave olarak, şiir yazma, paylaşma, düzenleme ve şiir hakkında yorumları kabul etmenin nasıl bir şey olduğuna dair bazı kişisel içgörüler edinmelerini sağlayacaktı. Bu kompozisyon deneyimleri, bu makalenin ana konusunu oluşturmaktadır ve aday öğretmenlerin yakında sınıflarındaki öğrenciler için uygulamaya başlayacakları 
bir dizi deneyimi ifade etmektedir. Bu amaçlar ve araştırmanın ana konusu, en başından itibaren aday öğretmenlerle açıkça paylaşılmıştır. Bizler, öğretmenlerle siber güvenlik ve çevrimiçi katılım/yayın ile ilgili etik konuları incelemeye ve onlara, katkılarını okuyabilecek izleyici(lerin) mizaçları hakkında derinlemesine düşünmeleri için bir fırsat sağlamaya da özen gösterdik.

Öğretmenler, her biri bir şiir türünün adıyla isimlendirilen karışık Birleşik Krallık ve Kanada gruplarına yerleştirildiler. Bu isimlendirmelerdeki niyetimiz sadece şiirin tanınabilir yönlerine atıfta bulunmaktı. Ancak, bu niyetimizin, soneler, destanlar veya gazeller yazmak zorunda kalacakları intimalinden dolayı ödü patlayan belirli gruplardaki bazı öğrenciler tarafından yanlış anlaşıldığını çabucak öğrendik. Onlara durumun böyle olmadığına dair güvence vermek için hızlıca hareket etmek durumunda kaldık ve Viki'nin gelecekteki sürümlerinde çok daha az korkutucu grup başlıkları kullanacağımıza söz verdik. Öğrencilerin tepkileri kendi içlerinde de ilginçti; çünkü hem konu bilgileri ile hem de şüphesiz kendilerinin de kariyerlerinin bir noktasında karşılaşacakları ve öğretmek zorunda kalacakları belirli şiir türlerini tartışma ve yazma konusundaki güven düzeyleri ile ilgili sorunları ortaya çıkardılar.

Her katılımcıdan bir dizi şiir tanımına yanıt olarak en az iki paylaşımda bulunmalarını istedik ki, böylece en azından Viki ortamının nasıl çalışığını görebilsinler. Bundan sonra, öğretmenler hem kendi grupları içinde hem de gruplar arasında devam eden çalışmaları paylaşmaya razı ve teşvik edildiler. Sıkı bir kontrole tabi tutmak yerine, ara sıra e-posta yoluyla ve bazı ders oturumlarında, onlara Viki'nin varlığını hatırlatmayı umduk. Ayrıca, kendilerinden birbirlerinin taslakları hakkında yorum yapmaları istendi ve hizmet öncesi öğretmen eğitimi veren hocalar da bu sürece düzenli olarak katıldı. 2008'in sonbaharında başlayan ikinci bir öğretmen adayları grubuyla, bu görevler isteğe bağlı görevlerle, pedagojinin çeşitli yönlerine daha yapılandırılmış bir odaklanma sağlamak için düzeltildi. İlk yılda Viki'ye olan hevesimizin katkılar üzerinde potansiyel olarak gereksiz bir etkiye sahip olabileceğini düşündüğümüz için ikinci grup hocalar tarafından çok daha az müdahaleye maruz kaldı.

Katılımcıların algıları ve şiir taslakları, çeşitli nitel yöntemler, yani, seminer tartışma notları, öğretmenler tarafından oluşturulan ve düzenlenen dijital eserler, diğer katılımcılar tarafından Viki'ye eklenen yorumlar ve düşünceler ve ders sona erdikten sonra yapılan anketler kullanılarak içeriden araştırma (Lankshear \& Knobel, 2003) yoluyla elde edildi. Veriler önce bağımsız kodlama kullanılarak analiz edildi; ardından, her iki araştırmacı tarafından paylaşıldı ve yeniden kodlandı. Gizliliği korumak için anonimleştirildi. Katılımcılardan yorumların ve taslak çalışmalarının yayınlanması için izin istendi ve alındı. Viki'yi oluşturan iki üniversite hocası da buna katıldı. Bu içeriden araştırma çalışması (Lankshear \& Knobel, 2003; Davies \& Merchant, 2007) tamamen sorunsuz değildi. Öğrencilerin taslakları hakkında yorum yaparken, ikimiz de öğretmen, değerlendirici, araştırmacı ve birimizin durumunda olduğu gibi, eserleri yayınlanmış bir şair olarak diğer rollerimizin ve deneyimlerimizin oldukça farkındaydık. Bunları bir kenara bırakmaya çalıştık, ancak bunlar kaçınılmaz olarak, müdahalelerimizi ve katılımcıların onlara tepki vermelerini veya kabullenmelerini etkiledi.

\section{Bulgular}

Bizler bu makalede öğretmen adaylarının Viki yazılarını analiz ederken, öncelikle onların kendilerini yazarlar olarak nasıl oluşturduklarını ve dijital üçüncü alanda birbirlerinin henüz tamamlanmamış eserlerine nasıl müdahale ettiklerini araştırmakla ilgilendik. Ayrıca, Viki'nin şiir yazma öğretimi konusundaki mesleki bilgi öğrenmelerine nasıl destek olduğunu ve onun pedagojik bir araç olma potansiyelini kendilerinin gelecekteki kullanımları için ne ölçüde belirlediklerini görmek istedik.

\section{Yazar olarak öğretmen adayları}

Barton (2005), Vikiler'e katılımın, bunun gerektirebileceği kişisel teşhir seviyesi nedeniyle, yazılarında kişisel seslerini ve kimliklerini bulmakta zorlananlar için uygun olmayabileceğini belirtmektedir. Yakın geçmişte, Wheeler ve Wheeler (2009) "bazı öğrencilerin, yazı üsluplarını uyarlama veya fikirlerini gizli bir dinleyicinin incelemesine açmaları gerektiğini anlarlarsa, katılım konusunda isteksiz olabileceklerini" iddia etmiştir (s. 4). Projemizde, biz belki de, daha önce de belirttiğimiz gibi, katılımcıların çoğunun daha önce şiir yazma deneyimi çok az olduğu veya hiç olmadığı için yazma üsluplarını uyarlamaktan daha fazlasını yapmalarını istedik. Etkileme arzusu ve diğer 
Bir Şiir Vikisi Kullanmak: Bu Ortam Dijital Bir Çağda İngilizce Öğretmen Adaylarının Şiir Yazma ve Şiir Yazmayı Öğretme Konusunda Meslekî Bilgi Öğrenmelerine Nasıl Destek Olabilir?

taraftan, ekranda gösterildiğinde taslağın (ve yazarın) savunmasızlı̆ııın kabulü anket yanıtlarında açıkça belirtildi.

Az sayıda katılımcı, önlerinde açılan boş sayfalarda anlaşııı bir şekilde intiyatlı davrandı ve ilk aşamalarda, boş sayfaların altındaki kutulara yorum göndermeyi tercih etti. (Ekranı okurken, bu kutular daha az belirgindir.) Bazı katılımcılar çekinerek boş bir sayfanın ince buzuna adım attılar ve bu üçüncü alanda kendilerini yazar olarak tanıtma konusunda ihtiyatlı davrandılar. Kendi eserlerini "kısa şiir" ya da "çok çok kaba taslak" olarak nitelendirdiler. Bir öğrenci şunu yazdı:

Vay, boş bir sayfa! .... işte başlıyorum! Bu şiirler son derece kaba, son derece düşünülmemiş ve sadece bir süre önce bir veya iki sayfaya karalanmıştı, eğer sayfalar [metinde yazıldığı şekilde] intikam peşinde olsaydı, sanırım ölmüştüm ... Her neyse, konu dışına çıktım, yorum yapmaktan çekinmeyin ve önceden özür dilerim, biraz kaygısız yorumlar yazmaya çalışacağım.

Bazı öğretmen adayları Viki'nin şiir yazma yönüne coşkuyla karşılık verdiler. İlk dönemde az sayıda kişi, hem kendi şiirleri için okuyucu aramak hem de sevdikleri şiir önerilerini paylaşmak için, farklı gruplara sık sık katkıda bulundu. Onlar, tribünlere oynama ve kısmi olarak bildikleri, ancak çoğunluğunu bilinmedikleri, izleyiciler ile ilişki geliştirme izlenimi verdiler. Bazıları yazar olarak kendileri üzerine düşünmeye ve başkalarının çalışmaları hakkında yorum yapmaya başladı. Örneğin, bir öğretmen adayı kendi gelişen yaratıcılı̆ı hakkında yorum yaptı ve şunu söyledi: "Sözcük seçimleri ile boğuşuyorum.". Dönem ilerleyip gruplara yerleştirmeler başladığında, diğer öncelikler kaçınılmaz olarak devreye girmeye başladı. Bir katılımcı Viki'de bir süre yok olmasından dolayı özür dileyerek şunu yazdı: "Şu öğretmenlik olayı ön plana çıktı".

Bazıları bu destekleyici ortamın kendilerine ilk defa kendi şiirlerini yazmaları ve paylaşmaları için güven verdiğini gördü. Biri şunu yazdı:

Itiraf etmeliyim ki, bu şimdiye kadar yazdığım ilk şiir... Bu sayfaya ve sen dostum

Haikus'a daha fazla katkıda bulunmaya çalışacağım. "Küller arasında dans ettik"e

[sitede yayınlanan başka bir şiir] hayranlık duyuyorum,

ve bence, senin gerçek bir yeteneğin var.

Diğer katılımcılar Viki tarafından sunulan çok ortamlılığı denemeye başladılar: yazılarına ilham veren görüntüleri ve diğer şiir sayfalarına yönlendirme bağlantılarını Viki'ye yapıştırdılar. Bir haiku şiiri yazdıktan sonra, bir öğrenci aynı adlı kendi eseri Küllerin arasında dans ettik'ten ilham alan çok güçlü ses ve görüntülerden oluşan bir film yaptı. Öğrenci şunları yazdı:

"Küllerin arasında dans ettik" şiirime eşlik etmesi için bu akşam hazırladığım bir videoyu ekledim (Haiku sayfasında). 'Şiirimi okuyan ben' videosu değil bu. Aslında, şiirdeki imgeyi destekleyen görsel bir montaj. Şiir kısmen dolaylı gerçeklik hakkında; bu yüzden, benim için aracı olsun diye çevrimiçi ücretsiz bir metinden ses'e dönüştürücü kullandım. Şiirimi yalnızca bunun içine yapıştırdım. Birleşim insan ritmi açısından biraz farklı ve umarım bu "okumaya" ürkütücü bir nitelik verir. Yorumları bekliyorum. Web kameraları ile daha az başarılı, bazı çalışmalar da denendi ve bu, gelecekte gelişmeye açık bir alan olmaya devam etmektedir. Projenin ikinci yılında, "dizüstü bilgisayar üniversitesi" olarak bilinen yerde konumlu Kanadalı öğretmen adayları, dâhili web kameraları olan yeni dizüstü bilgisayarlarla metin ve ses eklemenin çok ortamlı yollarını daha kapsamlı bir şekilde denemeye başladılar, ancak bu kaynaklar Birleşik Krallık grubunda yoktu.

Diğer katılımcıların taslak şiirlerine (herkese açık bir alanda) doğrudan müdahale nadiren oldu. Fountain (2005), müdahale etmemeyi çevrimiçi işbirlikli yaratıcı çalışmanın dikkate değer bir özelliği olarak tanımlar. Yine de, bazı aday öğretmenler belirli önerilerde bulundu. Örneğin, biri şöyle dedi: "Belli etmeden buraya "istekler" koyma şeklini seviyorum. Çok hoş. Sence başka bir şeye de uyabilir mi?" Bu yorumların ne ölçüde ele alındığı ve/veya onlar doğrultusunda nasıl hareket edildiği, eser hakkındaki Viki diyaloğunun, doğallıktan ve önemli bir gelişme göstermekten yoksun olarak dilbilgisel açıdan bütünlük sağlamaması sonucu çoğunlukla sınırlı kaldı. Bazı aday öğretmenler taslaklarını gözden geçirme niyetinde olduklarını belirttiler, ancak yalnızca küçük bir kısmı bunu aleni olarak çevrimiçi yaptı ve/veya yaptıkları değişiklikleri diğerlerine bildirdi. Bir katılımcı şu yorumu yaptı:

çok teşekkürler! "Dyke" ile kafiyeli olduğu için "like"ı çıkarmayı düşünmemiştim, çünkü ben aliterasyonu seviyorum ama çıkardığında kesinlikle işe yarıyor.... . 
Yeniden yazmanın nasıl gittiğinden haberim olsun :-).

Bir başkası şunu yazdı:

Sanırım kaldırmaya çalıştığım "and" ve "the"yı çok fazla kullandım. Teşekkürler A,

satır sonu bölme tavsiyesi vb. için. Onu yaptım ve bunun trafik ışıklarının sırasını

ve komutlarını daha iyi açıkladığını düşünüyorum. B, "itti"(pushed), "çekildi"

(pulled) ve "esnetti"(stretched)'nin gerçekten metin tarafından manipüle edilmesi önerini

de sevdim.

Bazı öğretmenler sessiz ziyaretçi olarak kalmayı tercih ederek nadiren katkıda bulundu. Ancak, bir yıllık, yoğun bir hizmet öncesi öğretmen eğitimi dersinde, öğretmen adaylarının sadece sınıfta teşhir olmanın olası korkularıyla yüzleşmek de dâhil olmak üzere birçok zorlukla yüzleşmek zorunda kalmadıkları, aynı zamanda pedagojik ve müfredat ile ilgili intiyaçlar tarafından da birçok yöne çekildikleri açıktı. Bazı öğrenciler için, Viki'ye katıım ve taslak çalışmayı paylaşmanın yol açabileceği riskler, bu aşamada öncelik vermeyi seçecekleri bir şey olmayabilirdi.

Taslak şiirler, genellikle bazı bağlamsal bilgilerle, bazen bir dönüt talebi ile veya şiiri yazma ile ilgili amaçların anlatımı ile sunuldu, yani, "Kafiyenin henüz tam olarak doğru olduğunu düşünmüyorum... Amaçlı olarak etrafı kolaçan ederek yürüyen bir tür kedi yürüyüşü yapıyorum." Bazı durumlarda, girişlerde bir yükümlülük duygusu belirgindi. Bazı öğretmenler işe, eski şiirleri (ilkokulda yazılmış olanları bile) veya proje başlamadan önce üzerinde çalışmaya devam ettikleri eserleri yayınlayarak başladı. Bu tür bir yaklaşımda belki de bir güvenlik veya emniyet duygusu vardı. Yavaş yavaş, bu yazarlar yeni eserlere geçtiler.

Toplamda 63 farklı şiir yayınlandı. Bazı öğretmenler 3 veya daha fazla şiir yazarken, diğerleri bu sayfalara hiç katkıda bulunmamayı tercih etti. Yayınlanan şiirlerin çoğu, öğretmen adaylarının devam ettikleri yükseköğrenim kurumlarında düzenlenen yazma atölyeleri veya zorunlu ders oturumlarında tartışıan şiirlerle bağlantılı olan, devam eden çalışmalardı. Bunlar, soneler, tablolar ilgili şiirler, haikular, beş mısralık esprili limerick şiirleri ve mermi şeklindeki şiir gibi diğer biçimlerdeki şiirleri içeriyordu. Mermi şiiri, yazarı tarafından Thomas Hardy'nin, Titanik'in batışından sonra yazılan ve buzdağı ile kötü şöhretli geminin ikiz doğumlarını ve kaderlerinde olan çarpışmasını anlatan "The Convergence of the Twain" (1976) (ikilinin yakınsaması) adlı şiiri ile ilgili ders içi tartışmasına atıfta bulunarak tanıtıldı.

"Üzerinde isim olan mermi" den

(anlamsız bir cinayet üzerine mısralar)

III

Şimdi takip et beni on altı yıl boyunca

Kahramanlarımızın ilk kucaklaşmasına

Kurşun hafifçe merkezine dokunur

Erkek bebeğin uyuyan yüzünün.

Nesneler için yazılan şiirler, mobilyalar için yazılan şiirler, tek heceli sözcükler kullanılan şiirler ve George Ella Lyon'un (1999) "Where I'm from" (Geldiğim yer)'inden esinlenen şiirler de yayınlandı.

Kısmen kendiliğinden ortaya çıkan eserlerden oluşan başka, farklı bir grup, aday öğretmenlerin mevcut durumlarından ilham aldı. Bunlar, gönderilen okullar, günlük seyahatler, ders konuları, içerikleri ve hatta bir keresinde, meslekî çalışmalar hocasının PowerPoint kullanımına odaklandı:

Kasıla kasıla yürüyor zeki ve güzel kadın

Bir slaytın ardından bir başka slayta

Hareketsizce oturuyor

Künt pedagojin

Parçalanıyor kafamda

Defalarca

Beş öğretmen adayı, belki de kendileri gibi düşünen yazarlardan bir karşılık almak için kendi gruplarından farklı gruplarda şiirler yayınladılar. illginçtir ki, bu beş kişiden dördü erkekti.

\section{Şiir yazmayı öğretmek ve Vikiler’i pedagojik bir araç olarak kullanmak}


Bir Şiir Vikisi Kullanmak: Bu Ortam Dijital Bir Çağda İngilizce Öğretmen Adaylarının Şiir Yazma ve Şiir Yazmayı Öğretme Konusunda Meslekî Bilgi Öğrenmelerine Nasıl Destek Olabilir?

Ders sona erdikten sonra yapılan anketteki yorumlar aracılığıyla, Viki'nin katılımcıların şiir yazma ve şiir yazma öğretimi üzerindeki etkisine bakıldığında, öğretmenlerin katıım sayesinde güven açısından geliştiklerini hissettiklerini görebiliyoruz (örneğin, "Artık kendi şiirlerimi yazmaya yetecek kadar kendime güveniyorum" ve [ben] "daha az korkuyorum... paylaşmaya daha çok istekliyim"). Daha fazla öğretmen adayı da ders sırasında Viki'ye daha fazla dâhil olmuş olmayı veya bunu yapacak özgüvene sahip olmuş olmayı diledi.

Viki'ye katılanlar da, katılmayanlar da, onun pedagojik bir araç olarak potansiyelinin farkına vardılar. Bir katılımcı şu yorumu yaptı: "Sınıf içi tartışmalarını ve çevrimiçi akran düzeltmelerini biçimlendirmek için bana harika bir model verdi." Kendine daha güvenen, Birleşik Krallıktaki Viki katılımcılarından biri, staja gönderildiği ikinci okulda bir Viki oluşturdu ve bunu İngilizce dersleri arasında hikâye taslaklarını paylaşmak için bir araç olarak çok başarılı bir şekilde kullandı. Kendine güvenen ikinci bir kullanıcı, hizmet öncesi öğretmen eğitimi yııının en sonunda, üç yeni taslak şiiri paylaşmak ve işbirlikli yaratıc yazma potansiyeli hakkındaki görüşünü söylemek için Viki'ye geri döndü:

Taslak hazırlama ve çalışma paylaşma fikrini seviyorum. Üstelik insanı teşvik ediyor

ve bir atölye ortamı oluşmasını kolaylaştırıyor gibi görünüyor. Dijital alan, insanların

çalışmalarını internet/viki vb. öncesinde mümkün olmayan bir şekilde sunmalarına

olanak verme açısından harika. vikilerde/bloglarda paylaşım yapmak insanın kendi

reklamını yapma öğesini ortadan kaldırıyor ve şiiri daha işbirlikçi hale getiriyor. Bence

şiir tam olarak böyle olmalı...

Her iki öğretmen de ilk öğretmenlik görevleri sırasında Vikiler'i kullanma niyetinde olduklarını belirtti. Ortamın potansiyelini ve onun sağladığı dijital alanda oluşturulabilecek metinleri gördüler. Bizim görüşümüze göre, Gudmundsdottir'in $(1995)$ pedagojik gözleriyle alanı yeniden inşa etmeye başladılar ve biz bu yılın ilerleyen zamanlarında, bu niyetlerini gerçekleştirip gerçekleştirmediklerini görmek için onlara ve gruptaki diğer öğretmen adaylarına ulaşacağız.

\section{Dijital çağda şiir yazmayı öğrenmek}

\section{Sonuçlar}

Öğretmen adayları dijital çağda şiir yazma konusunda kendi katılımlarından ne öğrendiler ve Viki, yazının bu türünün öğretilmesine ilişkin mesleki bilgi öğrenmelerine nasıl destek oldu? Yukarıdaki Viki gönderilerini, şiirlerini ve anket cevaplarını inceledikten sonra, bazı öğretmen adaylarının şiir yazma yeteneklerine güven duymak ve kendilerini yazar olarak ifade etmek için çeşitli türlerde şiir yazmaya başladıkları açıktır. Öğretmen adayları taslaklara müdahale etme yöntemlerini gördüler ve onları tecrübe ettiler. Bunlar kendi yaratıcılıklarını, eserlere eleştirel gözle bakabilmelerini ve ortaya çıkmakta olan öğretim becerilerini geliştirebilecek deneyimlerdir. Grubun bazı üyeleri, dijital ve çok ortamlı iletişimde teknolojik becerilerini yazılı, görsel ve işitsel ortamlar kullanımı yoluyla geliştirdiler. Ancak, sadece birkaç istisna dışında, şiirlerin çoğu yazıldıktan sonra, Grainger ve diğerlerinin dijital bir alanda "kafese konulmuş aslanları" (2005, s. 141) olarak kaldı. Her iki kurumda da düzenlenen şiir atölyelerinin, zorunlu öğretim oturumlarında kullanılan şiirlerle birlikte, paylaşılan eserlerin niteliği üzerinde bir etkisi olacağını umuyorduk (Kullanılan şiirler çeşitli tür, üslup ve icra tarzlarından seçilmişti ve dijital şiir örnekleri içermekteydi.). Bu şiirlerin bir ölçüde, çeşitli tür ve üsluptaki yazılı metinlerin sitede paylaşılmasında bir etkisi mutlaka olmuştur. Bununla birlikte, şiirlerin gizil gücü, örneğin: Podcast veya film olarak, henüz tam olarak fark edilememiştir. Bu, sitedeki şiirlerin hayal kırıklığı yaratan şiirler olduğu anlamına gelmez; tam tersine, Viki tarafından sunulan çoklu ortam olanaklarııı öğretmen adaylarııın çoğu tarafından kompozisyon aşamasında henüz kullanılmadığını gösterir.

\section{Olanaklar ve Viki kullanım seviyeleri}

Çalışmada farklı düzeylerde Viki kullanımı ortaya çıktı. Bazı öğretmen adayları Viki'nin potansiyelini gördüler ve bazı olanaklarından, özellikle işbirlikli kompozisyon yazma ile ilgili olanlardan, yararlanmaya başladılar. Diğerleri, işbirliğine olanak sağlayan bir ortam olarak potansiyelini gördüler, ancak buna katılmadılar. Belki de onlar gelecekte bir şekilde Viki kullanma konusunda daha az çekingen davranacaklardır. Bir ölçüde, tüm gruplar artık taslak paylaşma korkularının bir kısmını potansiyel olarak ortadan kaldırabilecek olan bir yönteme daha fazla aşina oldu. Hem taslakları görünür kılan hem 
de kendi yazdıkları hakkında bir sınıf ortamının veya bir saat uzunluğundaki dersin fiziksel sınırılıklarının ötesinde mümkün olabilecek olan daha fazla sayıda bakış açısı ve dönüt elde etmenin bir yolunu gördüler ve bazı durumlarda onu kullandılar.

Viki'nin, çoklu ortam olanaklarından ziyade, devam etmekte olan şiir metinlerini paylaşmak ve başkalarına geri bildirim sağlamak için sunduğu olanaklar, öğretmen adayları tarafından en çok kullanılanlar oldu. Bunun nedenlerini tam olarak tespit etmek zordur. Hiç şüphe yok ki, bu kısmen güven ile bağlantılıdır. Boş bir dijital alana adım atıp, şiirinizin ham sözlü hâliyle, destek veren ama büyük ölçüde tanıdık olmayan bir okuyucu kitlesine, kullanma konusunda çok emin olamayacağınız diğer ortamları da kullanmak zorunda kalmadan, teşhir edilmesinin zorluğunu küçümsememeliyiz. Ayrıca, öğretmen adaylarının eğitimlerinin ilk yılındaki bireysel öncelikleri ve çok ortamlı metinler oluşturma konusunda web kamerası ve dijital video gibi kaynaklara erişim ile ilgili sorunları vardır. Kanada grubunun Viki çalışmaları sırasında web kameralarına bir miktar erişimi olmasına rağmen, Birleşik Krallık'taki öğretmen adaylarının çoğunun ihtiyacı yeterince karşılanmış değildi.

\section{Ek Gelişmeler}

Şiiri daha iyi yazmak ve öğretmek için Viki’nin çok ortamlı imkânlarından yararlanmak isteriz. Ayrıca, öğretmen adaylarımızın gelişmekte olan mesleki icraatlarının diğer yönleriyle aralarında bağlantı kurmalarını sağlamak için daha fazla yazı türlerinde Viki kullanımını araştırmayı amaçlıyoruz. Bu sayede, katılımcılar belki de kendi yazdıklarına ve çevrimiçi kimliklerine daha fazla sahip çıkacak ve İngilizce öğretmenleri olarak, gelişen mesleki icraatlarının diğer yönleriyle daha bütünsel bağlantılar ve paralellikler kurarak, başkalarıyla daha rahat işbirliği yapacaklardır. Gelecekte hizmet öncesi öğretmen grupları için bu işbirliğine dayalı öğrenme ortamının daha fazla iyileştirilmesi ve kullanımı açısından, katılımcıların ihtiyaç ve arzularına göre üçüncü alanın kullanımı ve/veya işgali daha organik bir şekilde gelişsin diye, Viki'nin kullanımında daha az dayatılmış grup yerleştirmelerine, daha fazla yapılandırılmış (ancak isteğe bağ|ı) görevlere ve daha fazla esnekliğe ihtiyacı olduğunun farkına vardık.

Bu araştırmayı yürütmeye karar verirken, şiire olan ilgimiz ve birçok öğretmen adayının şiir öğretiminde karşılaştıkları pedagojik zorlukların farkında olmamız temel motive edici faktörler oldu. Viki, öğretmenlerin kariyerlerinin başlarında şiir yazma öğretiminde mesleki bilgi öğrenmesini desteklemek için yaratıcı riskler almak ve yaratıcı çalışmalara yönelik müdahaleleri bizzat görmek/denemek amacıyla destekleyici bir alan sunması bakımından potansiyel olarak değerli bir araçtır. Belirlediğimiz olanaklar, öğretmen adaylarının gelişmekte olan sınıf içi şiir yazma mesleki icraatlarına ve kendi şiir yazmalarına bir miktar etki etmiş gibi görünmektedir. Viki'nin uzun vadeli etkisini daha iyi bir şekilde değerlendirmek, şu an yeterlik sahibi olan bu öğretmenlerin çoğu sınıfta en az bir tam öğretim yılını tamamladıklarında, kendi şiir öğretme uygulamalarını daha da geliştirdiklerinde, sosyal yazılımlar ve onların içindeki diğer dijital alanların kullanımının öğretimin içine nasıl yerleştirileceği konusunda seçimler yaptıklarında mümkün olacaktır.

\section{TEŞEKKÜR}

Bu araştırmayı yapmamızı sağlayan İngilizce öğretmenlerine teşekkür ederiz.

\section{Kaynaklar}

Adisa (2002) What is Poetry? In A. Hoyles \& M. Hoyles (Eds.), (2002). Moving voices: Black performance poetry (pp. 128-129). London: Hansib Publications.

Andrews, R. (1991). The problem with poetry, Milton Keynes, UK: Open University Press.

Barton, M. (2005). The future of rational-critical debate in online public spheres. Computers and Composition, 22(2), 177-190.

Benton, P. (1984). Teaching Poetry: The rhetoric and the reality. Oxford Review of Education, 10(3), $319-327$.

Buckingham, D. (2003). Media Education: Literacy, learning and contemporary culture. Cambridge: Polity Press.

Burn, A., \& Durran, J. (2007). Media literacy in schools. London: Paul Chapman Publishing. 
Bir Şiir Vikisi Kullanmak: Bu Ortam Dijital Bir Çağda İngilizce Öğretmen Adaylarının Şiir Yazma ve Şiir Yazmayı Öğretme Konusunda Meslekî Bilgi Öğrenmelerine Nasıl Destek Olabilir?

Carrington, V. (2009). From Wikipedia to the humble classroom Wiki: why we should pay attention to Wikis. In V. Carrington \& M. Robinson (Eds.), Digital literacies (pp. 65-80). London: UKLA/Sage.

Department for Children, Schools and Families (DCSF). (2008). Teaching for progression: Writing. DCSF. Retrieved May 17, 2009, from http://nationalstrategies.standards.dcsf.gov.uk/node/154838 .

Davies, J., \& Merchant, G. (2007). Looking from the inside out: Academic blogging as new literacy. In M. Knobel \& C. Lankshear (Eds.), A new literacies sampler (pp. 168-197). New York: Peter Lang.

Davies, J., \& Merchant, G. (2009). Negotiating the blogosphere: Educational possibilities. In V. Carrington \& M. Robinson (Eds.), Digital Literacies (pp. 81-94). London: UKLA/Sage.

Doe, C. (2006) Lively language arts: The Digital Age invades the classroom. Multimedia \& Internet@Schools, 13(5), 30-33.

Dunn, J., Styles, M., \& Warburton, N. (1987). In tune with yourself. Cambridge: Cambridge University Press.

Dymoke, S. (2000). The teaching of poetry in secondary schools. Unpublished PhD thesis: University of Nottingham, UK.

Dymoke, S. (2007). Pre-service poetry teaching: Can the pursuit of "quality" also embrace creativity? Paper presented at American Educational Research Association (AERA) 2007 Annual Convention, Chicago, April 7-14, 2007.

Fountain, R. (2005). Wiki pedagogy. Retrieved August 8, 2008, from www.profeticorg/dossiers/dossiers-imprimer.php3 .

Gee, J. (2004). Situated language and learning: A critique of traditional schooling. London: Routledge.

Gioia, D. (2004). Disappearing ink: Poetry at the end of print culture. Minnesota: Graywolf Press.

Grainger, T., Goouch, K., \& Lambirth, A. (2005). Creativity and writing. London: Routledge.

Graves, D. (1981). Renters and owners. English Magazine, 8, 4 -7.

Graves, D. (1983). Writing: Teachers and children at work. London: Heinemann.

Grossman, P. (1991). What are we talking about anyway? Subject-matter knowledge of secondary English teachers. In J. Brophy (Ed.), Advances in research on teaching, Vol. 2 (pp. 245-264). Greenwich, Connecticut: JAI Press.

Gudmundsdottir, S. (1995). The narrative nature of pedagogical content knowledge. In H. McEwan \&K. Egan (Eds.), Narrative in teaching, learning and research (pp. 24-38). New York: Teachers College Press.

Hardy, T. (1976). "The convergence of the twain", The Complete Poems (pp. 306-7), London: Macmillan.

Harrison, B., \& Gordon, H. (1983). Metaphor is thought: Does Northtown need poetry? Educational Review, 35(3), 265-278.

Hauser, J. (2007). Media specialists can learn Web 2.0 tools to make school more fun. Computers in Libraries, 27(2), 6-7; 46-48.

Hennessey, S., Ruthven, K., \& Brindley, S. (2003). Teachers perspectives on integrating ICT into subject teaching: Commitment, constraints, caution and change. Journal of Curriculum Studies, 37(2), $155-192$.

Hughes, J. (2008). The "screen-size" art: Using digital media to perform poetry. English in Education, 42(2), 148-164.

Hughes, J., \& Dymoke, S. (submitted). "Wiki-Ed poetry": Transforming pre-service teachers' preconceptions about poetry and poetry teaching.

Johnson, B. (2009, August 12). Wikipedia approaches its limits. The Guardian (Technology). Retrieved August 17, 2009, from http://www.guardian.co.uk/technology/2009/aug/12/wikipediadeletionistinclusionist .

Knobel, M., \& Lankshear, C. (Eds.). (2007). A new literacies sampler. New York: Peter Lang.

Koch, K. (1970). Wishes, lies and dreams. New York: Harper and Row.

Koch, K. (1973). Rose, where did you get that red? New York: Vintage.

Lamb, B. (2004). Open spaces: Wikis, ready or not. EDUCAUSE Review, 39(5), 36-48. Retrieved August 8, 2008 from http://net.educause.edu/ir/library/pdf/ERM0452.pdf . 
Lankshear, C., \& Knobel, M. (2003). New literacies: Changing knowledge and classroom learning. buckingham: Open University Press.

Laurillard, D., Stratfold, M., Lucklin, R., Plowman, L. \& Taylor, J. (2000). Affordances for learning in a non-linear narrative medium. Journal of Interactive Media in Education. 2000, 2.

Lewis, C. (2007). New literacies. In M. Knobel \& C. Lankshear (Eds.), A new literacies sampler (pp. 22938). New York: Peter Lang.

Lyon, G. (1999). Where I'm from. Where I'm from: Where poems come from. Spring, Texas: Absey and Co.

Mathieson, M. (1980). The problem of poetry. Use of English, 31, 2.

National Curriculum Board. (2009). Shape of the Australian curriculum: English. NCB. Retrieved August 13, 2009, from http://www.ncb.org.au/verve/_resources/Australian_Curriculum_English.pdf.

New London Group. (1996). A pedagogy of multiliteracies: Designing social futures. Harvard Educational Review, 66(1), 60-92.

Nicholls, J. (1990, May, 11). Verse and verbiage. Times Educational Supplement. B27.

Ofsted (2007, July). Poetry in schools: A survey of practice. London: Ofsted. Retrieved December 7, 2009, from http://www.ofsted.gov.uk/Ofstedhome/Publications-andresearch/Browse-all-by/Education/Curriculum/English/Poetryin-schools/(language)/eng-GB .

Ontario Ministry of Education. (2007). The Ontario curriculum, Grades 9-12: English. Toronto: Queen's Printer for Ontario.

Ray, R. (1999). The diversity of poetry: How trainee teachers' perceptions affect their attitudes to poetry teaching. The Curriculum Journal, 10(3), 403-418.

Richardson, W. (2006). Blogs, wikis, podcasts, and other powerful web tools for classrooms. Thousand Oaks: Corwin Press.

Saskatchewan Education, (1998). Writing. English Language Arts 20: A curriculum guide for the secondary level. Regina, SK: Saskatchewan Education. Retrieved May 5, 2009 from http://www.sasked.gov.sk.ca/docs/ela20/copyright.html .

Shulman, L. (1986). Those who understand: Knowledge growth in teaching. Educational Researcher, 15, 4-13.

Steinkuehler, C. (2005). The new third place: Massively multiplayer online gaming in American youth culture. Tidskrift för lärarutbildning och forskning, Umea Universitet, 3(12), 17-32.

Stibbs, A. (1981). Teaching poetry. Children's Literature in Education, 12(1), 39-50. Training and Development Agency. (2007) Professional standards for qualified teacher status. London: Training and Development Agency for Schools. Thompson. L. (Ed.). (1996). The teaching of poetry: European perspectives. London: Cassell Education.

Vratulis, V., \& Dobson, T. (2008). Social negotiations in a wiki environment: A case study with preservice teachers. Education Media International, 45(4), 285-294.

Wheeler, S., \& Wheeler, D. (2009). Using wikis to promote quality learning in teacher training. Learning, Media and Technology, 34(1), 1-10.

Wyatt-Smith, C., \& Kimber, K. (2005). Valuing and evaluating student-generated online multimodal texts: Rethinking what counts. English in Education, 39(2), 22-43.

Yates, C. (1999). Jumpstart: Poetry in the secondary school. London: Poetry Society. 